\title{
Case Report: Aortic to right ventricular fistula after TAVR in a patient with transthyretin cardiac amyloidosis [version 1;
}

\section{peer review: 1 approved with reservations]}

\section{Sergio Garcia-Gomez (iD)1,2, Esther Gonzalez-Lopez 1,2, Juan Francisco Oteo (iD) 1,2}

${ }^{1}$ Cardiology, Hospital Universitario Puerta de Hierro, Majadahonda, Madrid, 28222, Spain

${ }^{2}$ Instituto de Investigación Sanitaria Puerta de Hierro - Segovia de Arana, Madrid, Spain

V1 First published: 10 Dec 2021, 10:1269

https://doi.org/10.12688/f1000research.75232.1

Latest published: $10 \mathrm{Dec} 2021,10: 1269$

https://doi.org/10.12688/f1000research.75232.1

\section{Abstract}

Aortic to right ventricular fistula formation after transcatheter aortic valve replacement (TAVR) is a rare complication. We describe the first case of an aorto-RV fistula after TAVR, conservatively managed, in a patient with concomitant aortic stenosis and wild-type transthyretin cardiac amyloidosis. Given that the underlying pathology may have implications, transthyretin cardiac amyloidosis screening in patients undergoing TAVR is warranted.

\section{Keywords}

Transthyretin cardiac amyloidosis, Aortic stenosis, Transcatheter aortic valve replacement, Ventricular fistula

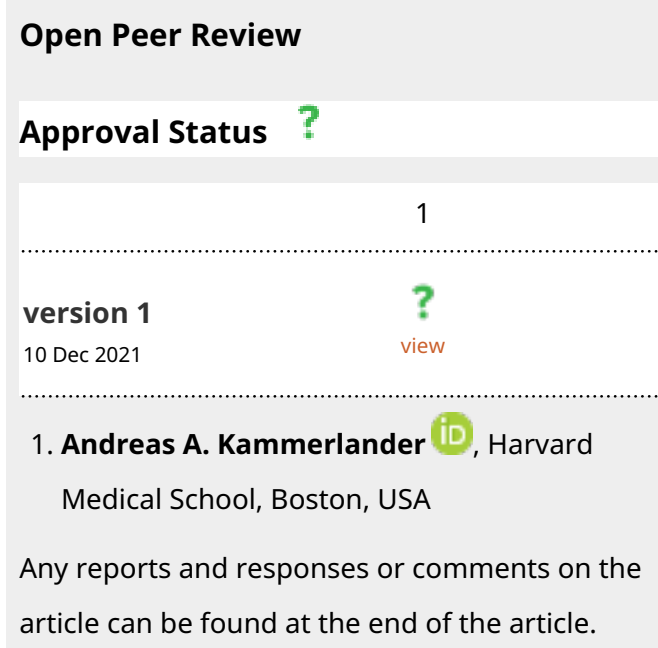

Corresponding author: Sergio Garcia-Gomez (sergiogarciagomez1302@gmail.com)

Author roles: Garcia-Gomez S: Conceptualization, Data Curation, Formal Analysis, Funding Acquisition, Investigation, Methodology, Project Administration, Resources, Software, Supervision, Validation, Visualization, Writing - Original Draft Preparation, Writing - Review \& Editing; Gonzalez-Lopez E: Conceptualization, Data Curation, Formal Analysis, Funding Acquisition, Investigation, Methodology, Project Administration, Resources, Software, Supervision, Validation, Visualization, Writing - Original Draft Preparation, Writing - Review \& Editing; Oteo JF: Conceptualization, Data Curation, Formal Analysis, Funding Acquisition, Investigation, Methodology, Project Administration, Resources, Software, Supervision, Validation, Visualization, Writing - Original Draft Preparation, Writing - Review \& Editing

Competing interests: Esther Gonzalez-Lopez reports speaking fees from Pfizer and Alnylam, consulting fees from Pfizer and Proclara, and research/educational support to her institution from Pfizer, Eidos and Alnylam. Sergio Garcia Gomez and Juan Francisco Oteo have nothing to disclose

Grant information: This work was supported by grants from the Instituto de Salud Carlos III (PI18/0765 \& PI20/01379) and Fundación de investigación Biomédica del Hospital Puerta de Hierro.

The funders had no role in study design, data collection and analysis, decision to publish, or preparation of the manuscript.

Copyright: $\odot 2021$ Garcia-Gomez S et al. This is an open access article distributed under the terms of the Creative Commons Attribution License, which permits unrestricted use, distribution, and reproduction in any medium, provided the original work is properly cited.

How to cite this article: Garcia-Gomez S, Gonzalez-Lopez E and Oteo JF. Case Report: Aortic to right ventricular fistula after TAVR in a patient with transthyretin cardiac amyloidosis [version 1; peer review: 1 approved with reservations] F1000Research 2021,10 :1269 https://doi.org/10.12688/f1000research.75232.1

First published: 10 Dec 2021, 10:1269 https://doi.org/10.12688/f1000research.75232.1 


\section{Abbreviations}

AS: aortic stenosis

ATTRwt: wild-type transthyretin cardiac amyloidosis

CA: cardiac amyloidosis

CTS: carpal tunnel syndrome

HF: heart failure

$\mathrm{RV}$ : right ventricular

TAVR: transcatheter aortic valve replacement

\section{Introduction}

There is a high prevalence of wild-type transthyretin cardiac amyloidosis (ATTRwt) among patients with degenerative aortic stenosis (AS). We describe the first case of an aortic to right ventricular (RV) fistula after transcatheter aortic valve replacement (TAVR).

\section{Patient information}

An 88-year-old Caucasian, retired, male patient was referred for transcatheter aortic valve replacement (TAVR) due to degenerative severe AS and heart failure (HF). He was first evaluated in 2015, following the diagnosis of atrial fibrillation and a systolic murmur.

Regarding his past medical history, he was a former smoker and had known dyslipidemia. Additionally, he had undergone bilateral carpal tunnel syndrome (CTS) intervention in 2015 and 2016.

\section{Clinical findings}

On top of moderate-to-severe aortic stenosis (maximal mean gradient: $32 \mathrm{mmHg}$; area: $0.9 \mathrm{~cm}^{2}$ ), his first echocardiogram revealed mild left ventricular hypertrophy, preserved systolic function and a severely dilated left atrium.

Given his previous history of CTS, cardiac amyloidosis diagnosis workup was started. Plasma cell dyscrasia was ruled out and technetium-99m $\left({ }^{99 \mathrm{~m}-} \mathrm{Tc}\right) 3,3$-diphosphono-1,2-propanodicarboxylic acid (DPD) scintigraphy showed an intense myocardial uptake, establishing a non-invasive diagnosis of concomitant ATTRwt, after excluding transthyretin (TTR) mutations.

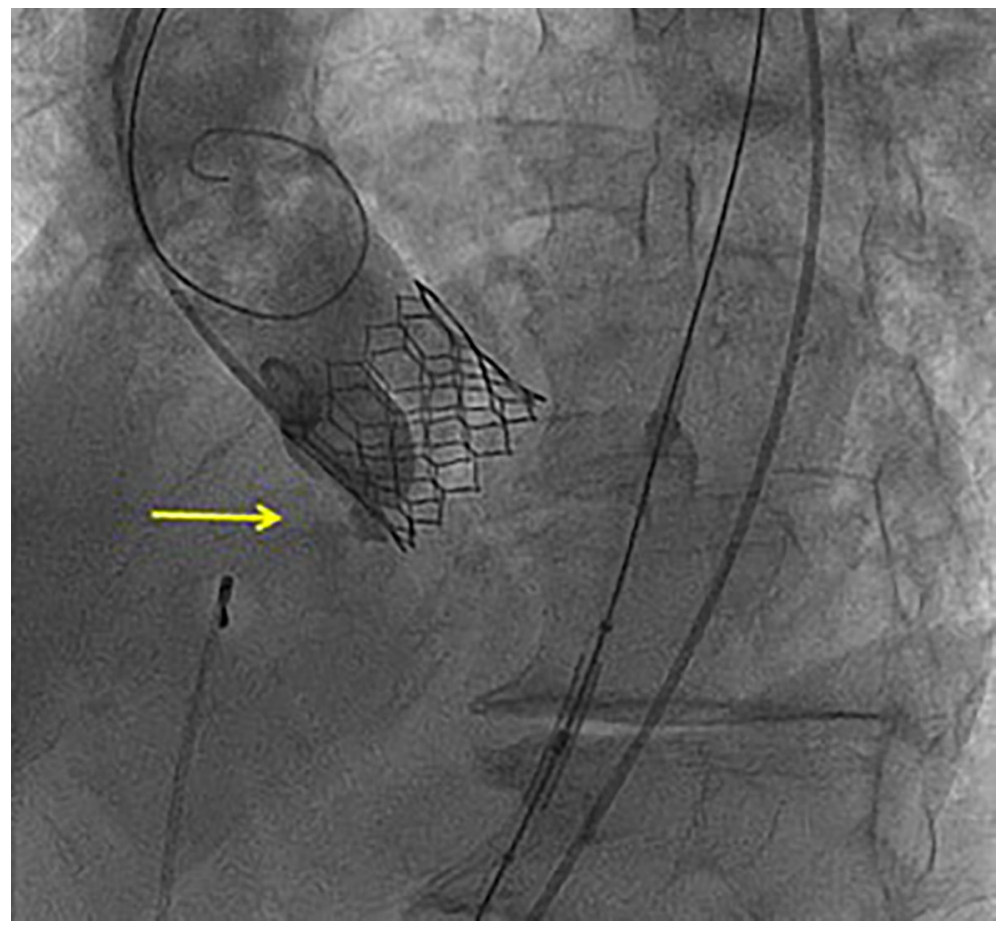

Figure 1. Aortic to right ventricular fistula after transcatheter aortic valve replacement observed by angiography. 
Video 3: 75232-V1-1-Video 3.avi

1 data file

https://doi.org/10.6084/m9.figshare.17122211 15

\section{Video 4: 75232-V1-1-Video 4.avi}

1 data file

https://doi.org/10.6084/m9.figshare.17122226 ${ }^{16}$

\section{Video 5: 75232-V1-1-Video 5.avi}

1 data file

https://doi.org/10.6084/m9.figshare.17122241 ${ }^{17}$

\section{Video 6: 75232-V1-1-Video 6.avi}

1 data file

https://doi.org/10.6084/m9.figshare. $17122265^{18}$

\section{Discussion}

AS is the most common valve disease in the elderly population. Nearly $5 \%$ of patients aged 75 years and over have at least moderate $\mathrm{AS},{ }^{1}$ with a prevalence of $>4 \%$ in octogenarians.

Cardiac amyloidosis (CA) has been traditionally associated to a restrictive cardiomyopathy, caused by the extracellular deposition of proteins in the myocardium. Primary or amyloid light-chain (AL) amyloidosis and transthyretin cardiac amyloidosis (in its hereditary or wild-type (ATTRwt) forms) are the most common subtypes of CA. Recently, transthyretin amyloidosis (ATTR) has been considered much more prevalent than AL. ${ }^{2}$

Amyloid can infiltrate all components of the heart, from the conduction system to vessels. Amyloid infiltration has typically been associated with atrioventricular valve infiltration, but recently, the coexistence of AS and ATTRwt has emerged as a very prevalent clinical scenario. ${ }^{2}$

In 2016 a histological report revealed that occult ATTRwt had a prevalence of 5.3\% among patients undergoing surgical aortic valve replacement due to severe calcific aortic stenosis. The subjects in the report were predominantly males, with a mean age of 75 years old. ${ }^{3}$

A higher prevalence was found later in screened populations undergoing TAVR as these patients tend to be older. ${ }^{3}$ An American study prospectively screened AS patients undergoing TAVR, using technetium pyrophosphate scintigraphy and found a prevalence of $16 \%$ among them. ${ }^{4}$ More recently, a European study observed that the combination of AS and amyloid is common and affects around one in eight elderly patients with severe AS being considered for TAVR. ${ }^{5}$ Therefore, clinical, ECG and imaging red flags for CA should be systematically searched for in patients with AS to identify concomitant ATTRwt.

Both entities, AS and ATTRwt, share a common demographic and clinical profile, being considered part of the aging process. ${ }^{6}$ There is increasing data pointing out to a causative link between them though. ${ }^{6}$ Oxidative stress, inflammation and extracellular remodeling may be involved in TTR amyloidogenic process ${ }^{6}$ and these factors are also a central part of AS' pathophysiology. Thus, it is possible that amyloid deposits could be induced or accelerated in patients with AS.

The association between AS and CA is not just prevalent, but also dangerous. Some authors ${ }^{3,7}$ have described a higher mortality in patients with AS and CA compared to those with isolated AS, while in a recent cohort, mortality was not affected among those patients with ATTR and AS undergoing TAVR. ${ }^{8}$ The worse prognosis in these patients could be mainly caused by CA, even after valve replacement. To support this, the latest cohort was presented with an increase of HF admissions after TAVR. ${ }^{8}$ 
According to different groups, ${ }^{9,10}$ either repeated balloon valvuloplasties or TAVR is the best therapeutical options considering these patients' frailty. Nowadays, TAVR is a procedure that commonly sees favorable outcomes, but some frequent complications (conduction disturbances, ...) might occur. Nonetheless, aortic to RV fistula formation is a rare complication $\left(0.004 \%\right.$ according to reported cases). ${ }^{11}$ This unusual complication does not often require repair and is reversible in most cases.

This case represents a typical example of diagnosis and management of AS and concomitant ATTRwt in an elderly patient. Low-flow, low-gradient AS has been shown to be a frequent form of AS presentation in ATTR. ${ }^{4}$ In this setting, the dobutamine stress test plays a crucial role in order to correctly evaluate AS's severity and guide management. Attitude regarding AS in patients with CA should be personalized.

Our case illustrates a rare complication of an aortic to RV fistula. Although similar cases have been previously reported, ${ }^{11}$ to our knowledge, this is the first case of an aorto-RV fistula after TAVR in a patient with concomitant AS and ATTRwt. Aortic to RV fistula seems to be a rare complication, and cardiac amyloidosis was confirmed in just this case out of the four at our own center. Of note, it is the only one in which the fistula did not resolved during follow-up and we hypothesize its relationship with tissue's fragility due to amyloid deposition.

The exact mechanism for fistula development after TAVR is not fully understood. Possible reasons to justify its development include congenital or acquired sinus of Valsalva aneurysms, trauma, or infections. Most cases of aortic to RV fistulas have been described in patients in whom a balloon-expanded transcatheter valve was used, ${ }^{11}$ possibly conditioned by trauma and oversizing. In this case, we believe that amyloid deposits on the aortic valve annulus might have led to a more friable substratum, making this case prone to complications, mainly complete AV block and aortic to RV fistula.

Several studies have found myocardial amyloid deposits in a significant percentage of patients with AS. Different authors have identified amyloid deposits in prosthetic valves explanted ${ }^{3}$ and in endomyocardial biopsies from basal left ventricle septum. ${ }^{3}$ Histological analysis of the interventricular septum performed by Moreno $e a^{12}$ in a patient who developed a complete AV block after TAVR discovered two different potential mechanisms to explain the patient's complication: a localized hematoma at the site of aortic valve prosthesis expansion, which could justify trauma damage on the conduction system; and amyloid deposits.

\section{Conclusions}

Generally, conservative management with annual re-evaluation is accepted in ventricular fistulas. Except when significant symptom development or hemodynamic instability occurs. Based on our own experience, a conservative approach is an adequate option, even in cases with concomitant ATTRwt.

\section{Learning objectives}

1. To remind the importance of extensive clinical and imaging evaluation before transcatheter aortic valve replacement.

2. To emphasize the high prevalence of ATTRwt among patients with degenerative aortic stenosis undergoing TAVR and the need of amyloid screening in this clinical scenario.

3. To highlight the role of dobutamine stress echocardiogram in this setting.

4. To increase awareness about possible TAVR complications in patients with concomitant AS and ATTRwt and how to approach these cases in order to minimize them.

\section{Data availability}

Underlying data

All data underlying the results are available as part of the article and no additional source data are required.

\section{Extended data}

Figshare: Video 1: Aortic to right ventricular fistula after transcatheter aortic valve replacement observed by fluoroscopy, https://doi.org/10.6084/m9.figshare.17122124.v1. ${ }^{13}$

Figshare: Video 2: Aortic to right ventricular fistula after transcatheter aortic valve replacement. Control echocardiogram (subcostal view) during follow-up, https://doi.org/10.6084/m9.figshare.17122181.v1. ${ }^{14}$ 
Figshare: Video 3: Aortic to right ventricular fistula after transcatheter aortic valve replacement. Control echocardiogram (parasternal long axis view) during follow-up, https://doi.org/10.6084/m9.figshare.17122211.v1. ${ }^{15}$

Figshare: Video 4: Aortic to right ventricular fistula after transcatheter aortic valve replacement. Control echocardiogram (parasternal short axis view) during follow-up, https://doi.org/10.6084/m9.figshare.17122226.v1. ${ }^{16}$

Figshare: Video 5: Aortic to right ventricular fistula after transcatheter aortic valve replacement. Control echocardiogram (apical five chamber view) during follow-up, https://doi.org/10.6084/m9.figshare.17122241.v1.17

Figshare: Video 6: Aortic to right ventricular fistula after transcatheter aortic valve replacement. Control echocardiogram (zoom on apical five chamber view) during follow-up, https://doi.org/10.6084/m9.figshare.17122265.v1. ${ }^{18}$

Data are available under the terms of the Creative Commons Attribution 4.0 International license (CC-BY 4.0).

\section{Written informed consent}

Written informed consent from the patient for the use and publication of the patient's data was obtained.

1. Thaden JJ, Nkomo VT, Enriquez-Sarano M: The global burden of aortic stenosis. Prog. Cardiovasc. Dis. 2014; 56: 565-571. Publisher Full Text

2. Garcia-Pavia P, Domínguez F, Gonzalez-Lopez E: Transthyretin amyloid cardiomyopathy. Med. Clin. (Barc.). 2020; 156: 126-134. Publisher Full Text

3. Treibel TA, Fontana M, Gilbertson JA, et al.: Occult Transthyretin Cardiac Amyloid in Severe Calcific Aortic Stenosis: Prevalence and Prognosis in Patients Undergoing Surgical Aortic Valve Replacement. Circ. Cardiovasc. Imaging. 2016; 9: e005066. Publisher Full Text

4. Castaño A, Narotsky DL, Hamid N, et al.: Unveiling transthyretin cardiac amyloidosis and its predictors among elderly patients with severe aortic stenosis undergoing transcatheter aortic valve replacement. Eur. Heart J. 2017; 38: transcathet

PubMed Abstract | Publisher Full Text

5. Scully PR, Patel KP, Treibel TA, et al.: Prevalence and outcome of dual aortic stenosis and cardiac amyloid pathology in patients referred for transcatheter aortic valve implantation. Eur. HeartJ. 2020; 41: 2759-2767.

PubMed Abstract | Publisher Full Text

6. Galat A, Guellich A, Bodez D, et al.: Aortic stenosis and transthyretin cardiac amyloidosis: the chicken or the egg? Eur. Heart J. 2016; 37: 3525-3531. Publisher Full Text

7. Cavalcante JL, Rijal S, Abdelkarim I, et al.: Cardiac amyloidosis is prevalent in older patients with aortic stenosis and carries worse prognosis. J. Cardiovasc. Magn. Reson. 2017; 19: 98.

PubMed Abstract | Publisher Full Text

8. Rosenblum H, Masri A, Narotsky DL, et al.: Unveiling outcomes in coexisting severe aortic stenosis and transthyretin cardiac amyloidosis. Eur. J. Heart Fail. 2020; 23: 250-258. PubMed Abstract | Publisher Full Text

9. Bordoni B, Moretti C, Marrozzini C, et al.: Repeated Aortic Balloon Valvuloplasty in Elderly Patients With Aortic Stenosis Who Are Not Candidates for Definitive Treatment. J. Invasive Cardiol. 2015 Dec; 27(12): E277-84. PubMed Abstract

10. Alsamarrai A, Wang TKM: Balloon aortic valvuloplasty for severe aortic stenosis: single-centre contemporary patterns and experience. N. Z. Med. J. 2021 Sep 3; 134(1541): 123-129. PubMed Abstract

11. Konda MK, Kalavakunta JK, Pratt JW, et al.: Aorto-right Ventricular Fistula Following Percutaneous Transcatheter Aortic Valve Replacement: Case Report and Literature Review. Heart Views. 2017; 18: 133-136. PubMed Abstract | Publisher Full Text

12. Moreno R, Dobarro D, López de Sá E, et al.: Cause of complete atrioventricular block after percutaneous aortic valve implantation: insights from a necropsy study. Circulation. 2009; 120: e29-e30. PubMed Abstract | Publisher Full Text

13. Gomez SG, Gonzalez-Lopez E, Oteo JF: Video 1: Aortic to right ventricular fistula after transcatheter aortic valve replacement observed by fluoroscopy. f1000research.com. Media. 2021 Publisher Full Text

14. Gomez SG, Gonzalez-Lopez E, Oteo JF: Video 2: Aortic to right ventricular fistula after transcatheter aortic valve replacement. Control echocardiogram (subcostal view) during follow-up. f1000research.com. Media. 2021. Publisher Full Text

15. Gomez SG, Gonzalez-Lopez E, Oteo JF: Video 3: Aortic to right ventricular fistula after transcatheter aortic valve replacement. Control echocardiogram (parasternal long axis view) during follow-up. f1000research.com. Media. 2021. Publisher Full Text

16. Gomez SG, Gonzalez-Lopez E, Oteo JF: Video 4: Aortic to right ventricular fistula after transcatheter aortic valve replacement. Control echocardiogram (parasternal short axis view) during follow-up. f1000research.com. Media. 2021. Publisher Full Text

17. Gomez SG, Gonzalez-Lopez E, Oteo JF: Video 5: Aortic to right ventricular fistula after transcatheter aortic valve replacement. Control echocardiogram (apical five chamber view) during follow-up. f1000research.com. Media. 2021. Publisher Full Text

18. Gomez SG, Gonzalez-Lopez E, Oteo JF: Video 6: Aortic to right ventricular fistula after transcatheter aortic valve replacement. Control echocardiogram (zoom on apical five chamber view) during follow-up. f1000research.com. Media. 2021.

Publisher Full Text 


\section{Open Peer Review}

\section{Current Peer Review Status: ?}

\section{Version 1}

Reviewer Report 07 February 2022

https://doi.org/10.5256/f1000research.79075.r120430

(c) 2022 Kammerlander A. This is an open access peer review report distributed under the terms of the Creative Commons Attribution License, which permits unrestricted use, distribution, and reproduction in any medium, provided the original work is properly cited.

\section{Andreas A. Kammerlander}

Cardiovascular Imaging Research Center, Massachusetts General Hospital, Harvard Medical School, Boston, MA, USA

Nice case of severe AS and concomitant cardiac TTR-Amyloidosis.

I would suggest the following:

- Currently, only the bilateral carpal tunnel syndrome is presented as hint for cardiac amyloidosis (CA). This should be expanded to: discordance of ECG and LV hypertrophy on imaging, apical sparing in strain analysis, etc.

- Aortic to RV fistula is a rare but known complication. It is a valid hypothesis that CA patients may be more prone to such an adverse event, however, there is no data to back this up. Hence, this is speculative and should be stated as such.

- I would include the scintigraphy image for the readers.

- Your comment that CA in patients with AS is "dangerous" should be revised and discussed more critically. See e.g. 10.1016/j.jacc.2020.11.006 where treated (with TAVR) CA-AS patients performed similarly to lone AS patients.

\section{References}

1. Nitsche C, Scully P, Patel K, Kammerlander A, et al.: Prevalence and Outcomes of Concomitant Aortic Stenosis and Cardiac Amyloidosis. Journal of the American College of Cardiology. 2021; 77 (2): 128-139 Publisher Full Text

Is the background of the case's history and progression described in sufficient detail? Partly

Are enough details provided of any physical examination and diagnostic tests, treatment 
given and outcomes?

Partly

Is sufficient discussion included of the importance of the findings and their relevance to future understanding of disease processes, diagnosis or treatment?

Partly

Is the case presented with sufficient detail to be useful for other practitioners?

Yes

Competing Interests: No competing interests were disclosed.

Reviewer Expertise: cardiovascular imaging, valvular heart disease, cardiac amyloidosis, coronary heart disease, cardiovascular magnetic resonance imaging.

I confirm that I have read this submission and believe that I have an appropriate level of expertise to confirm that it is of an acceptable scientific standard, however I have significant reservations, as outlined above.

The benefits of publishing with F1000Research:

- Your article is published within days, with no editorial bias

- You can publish traditional articles, null/negative results, case reports, data notes and more

- The peer review process is transparent and collaborative

- Your article is indexed in PubMed after passing peer review

- Dedicated customer support at every stage

For pre-submission enquiries, contact research@f1000.com 